investigations, and it is not only of great importance from a purely entomological point of view, inasmuch as the rearing of galls yields insects which belong to the parasites and inquilines, which could not probably be obtained in any other way, but it is so also because it binds together inseparably two great fields of human investigation, botany and entomology. But the study of plant-galls has moreover a deep practical interest in two other directions, in an industrial and agricultural regard. An all-sided consideration of the subject should not leave these sides of it unattended to.

\title{
ON THE RELATIONS OF FUNGI TO GALLS AND TO LARVAE OF CECIDOMYIA LIVING IN GALLS.
}

\author{
BY HERMANN AUGUST HAGEN, CAMBRIDGE, MASS.
}

[Reprint, with slight amendment, of an abstract with the same title, by Hermann August Hagen (Canadian entom., July 1885, v. I7, p. 136-137), of a review, by Friedrich August Wilhelm Thomas (Irmischia, I885, v. 5, p. 4- ), based on a record by Fritz Ludwig (Botan. centralblatt, v. 20, p. 356-) of W: Trelease's "Notes on the relations of two cecidomyians to fungi" (Psyche, Aug-Sep. 1884, v. 4, p. 195-200), Trelease's paper not having been seen by Thomas.]

Larvae of Cecidomyia living in the spore-layers of uredineae are also found in Thuringia, Germany. In fact the discovery of the community in the same layer of two otherwise very different parasites is at first somewhat wonderful and startling. The right explanation will be a double symbiosis of a phanerogamous plant and a fungus, and of a fungus and an entomozoon. Years ago I received from Gotha such larvae out of the rust-fungus of Rosa. A similar manner of living is known in Germany for Diplosis coniophaga Winnertz and for D. caeomatis Winn. Their larvae were found by F. Loew in the rust-fungus of several plants (cf. Verh. Zool.-bot. ges. Wien, I874, p. 155-). I am able to add two new facts. I found larvae of Cecidomyia on Vaccinium uliginosum in the spore-layers of Thecospora myrtillina Karsten (Melampsora vaccinii Alb. et Schn.), on the Beerberg in the Thueringerwald. The other one was sent to me by Dr. E. Levier, from Florence,
Italy. The leaves of Tanacetum bal. samita L. (Erba di Santa Maria) had, in the Puccinia tanaceti balsamitae D C., many small red larvae of Cecidomyia. I am not of opinion that this guard is of prominent advantage for the plant. The enormous numbers of the spores of the rust-fungus will scarcely be diminished by these larvae to any extent, that the guard may be considered to be a practical advantage for the plant.

The second point of interest in $\mathrm{Mr}$. Trelease's paper is that the larvae open the way for the fungus in the plants. I may state as an analogous fact, that here the pustulae and pocks on the leaves of pomaceae, made by Phytoptus, are not rarely filled by fungi, especially by the carbonized ones. The last plant I received by the late Alex. Braun, in 1877 , from Blankenburg, Harz, was a leaf of Sorbus aucuparia, with fungus immigrated in the galls of the mites. 

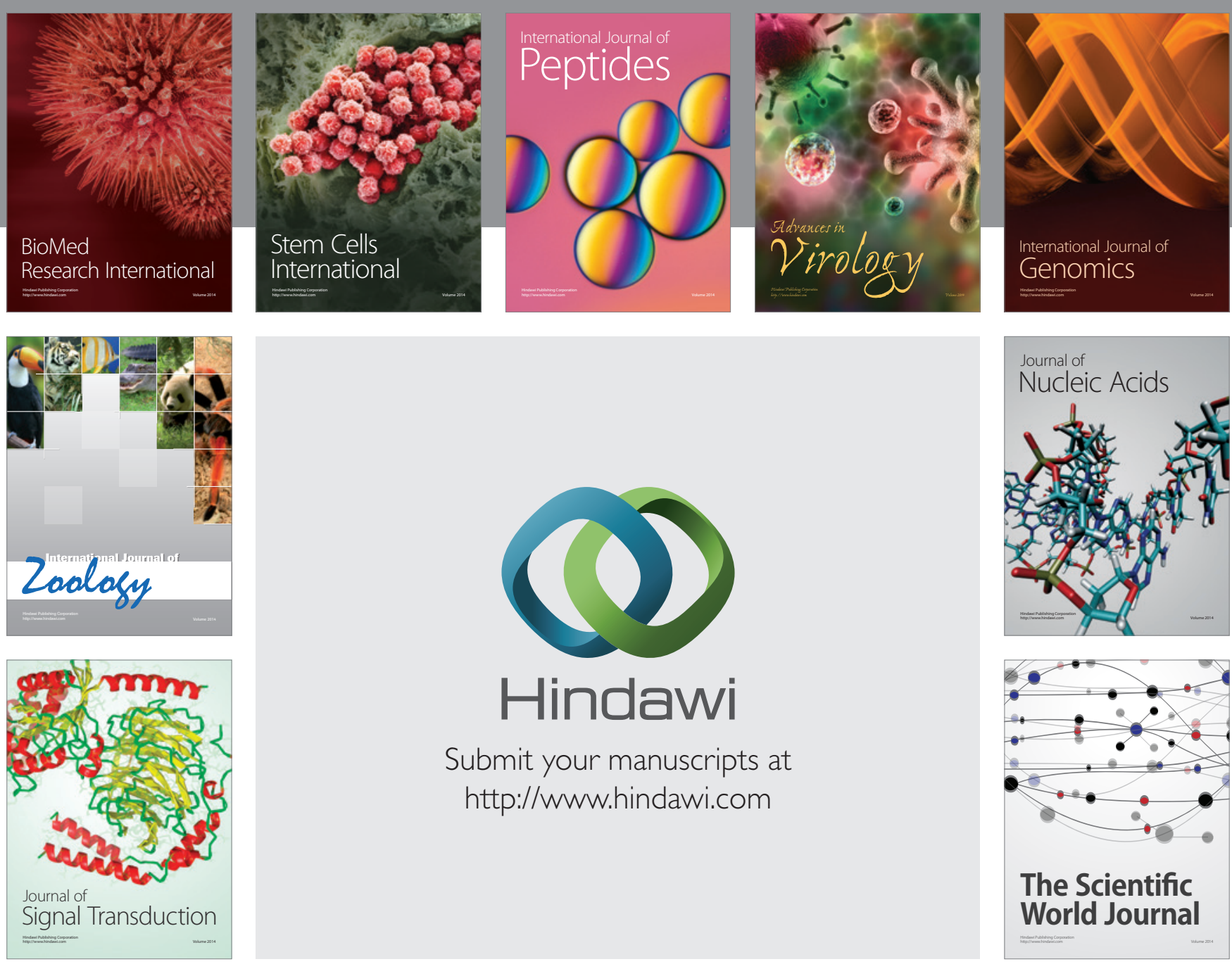

Submit your manuscripts at

http://www.hindawi.com
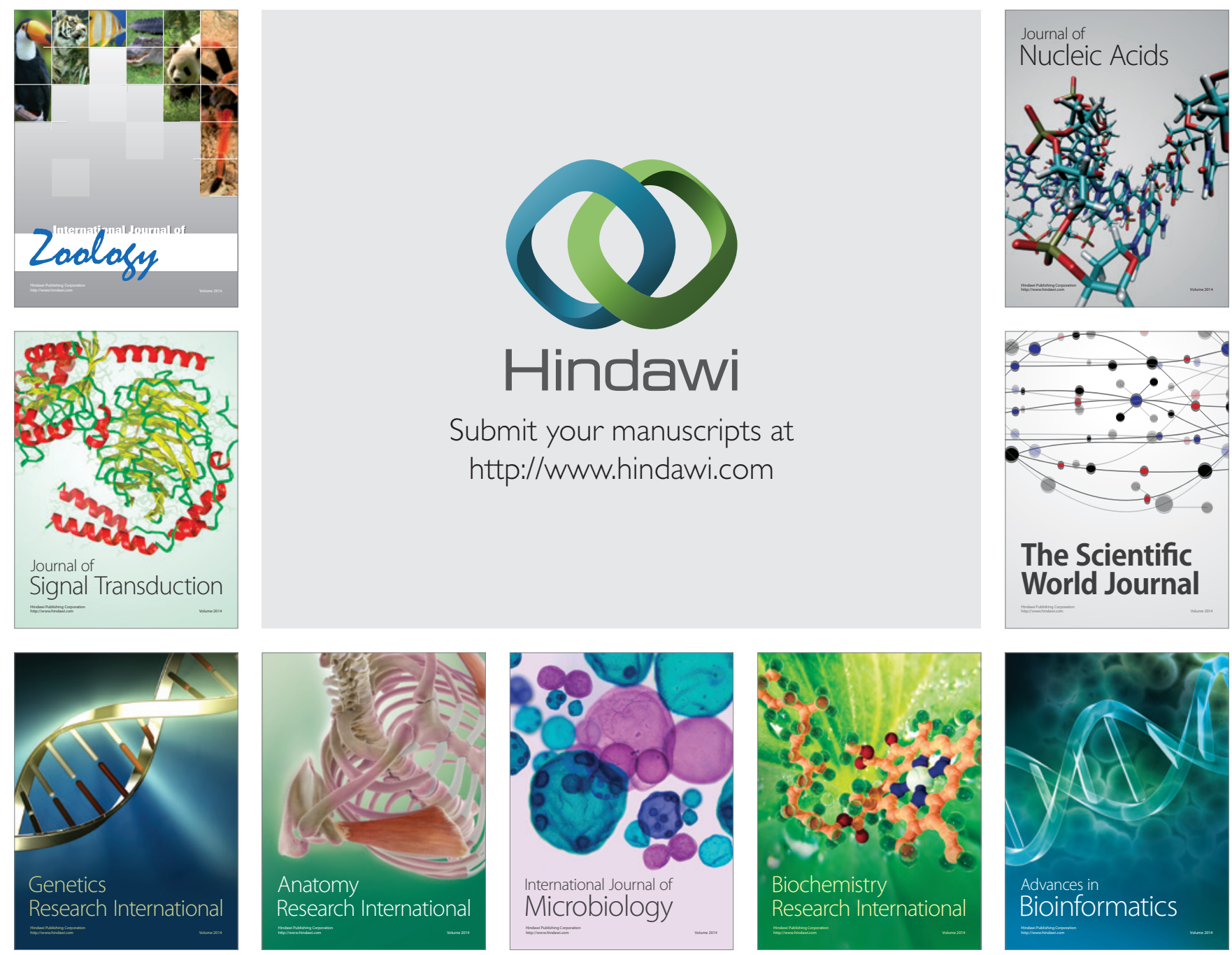

The Scientific World Journal
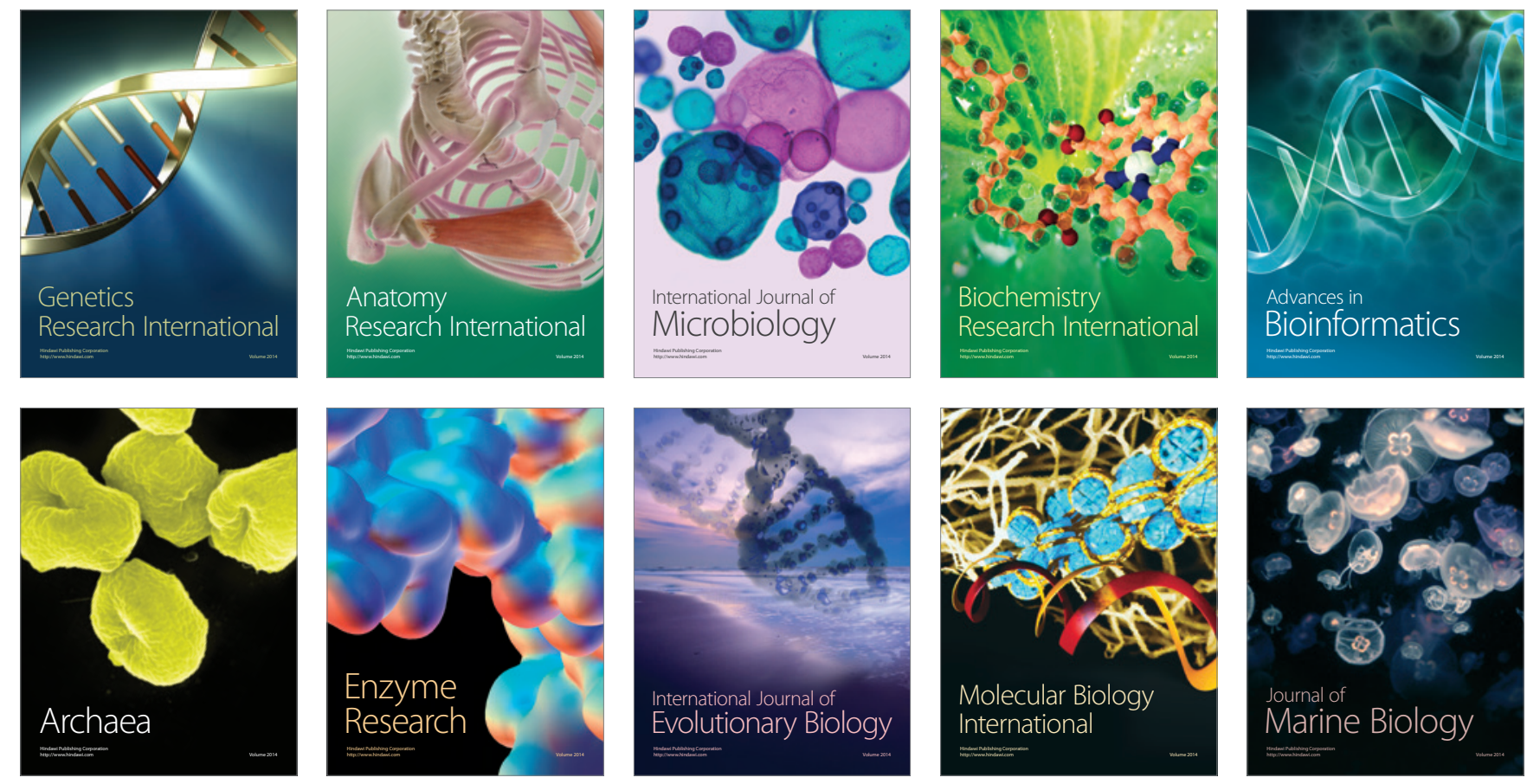